\title{
JOSÉ DONOSO: \\ LA CONJETURA COMO ARTE NARRATIVO
}

\section{Marcelo Maturana}

Universidad de Chile

\begin{abstract}
Resumen: Este texto corresponde, salvo unos mínimos ajustes, a la evocación de José Donoso leída durante una mesa redonda en la Casa de América, en Madrid, en octubre de 2007, con motivo de unas jornadas de homenaje al escritor chileno. El autor narra detalles de su trabajo con José Donoso mientras fue su editor, y aventura una audaz interpretación de su obra, especialmente de Conjeturas sobre la memoria de mi tribu, uno de sus últimos libros.
\end{abstract}

Palabras clave: José Donoso, narrativa, escritores del Boom, Alfaguara, editor, taller literario, literatura chilena, novela.

Recibido: noviembre 2007; aceptado: septiembre 2007.

\section{JOSÉ DONOSO: CONJETURE AS A NARRATIVE}

ART

Abstract: Except for some minor adaptations, this is a rendering of the tribute to Jose Donoso read at a round table held at Casa de America in Madrid, in October 2007, as part

Marcelo Maturana (Londres, 1955). Estudió Antropología en la Universidad de Chile. Actualmente es editor literario free-lance y columnista en medios escritos. Ha sido también crítico literario. Dirección electrónica: marcelovacmm@gmail.com.

José Donoso Yáñez nació en Santiago de Chile, el 5 de octubre de 1924. Durante 2014 se celebran los noventa años de su nacimiento. 
of a symposium in honor of the Chilean writer. The author narrates details of his work with Jose Donoso while he was an editor and he renders an audacious interpretation, especially of Conjectures on the Memory of My Tribe, one of the later works by this great Chilean novelist.

Keywords: José Donoso, narrative, Latin american boom, Alfaguara, literaty editor, writing workshop, chilean literature, novel.

Received: November 2007; accepted: September 2013.

I magino que algunos esperan de mí, hoy, que hable del extinto José Donoso desde el punto de vista de un crítico literario, o incluso como el editor que, en los últimos años del escritor, estuvo encargado de revisar los manuscritos de la novela Donde van a morir los elefantes, y luego de los relatos semificticios de Conjeturas sobre la memoria de mi tribu. Querrán ustedes, tal vez (puedo equivocarme), saber cómo se pondera a Donoso en el contexto de la narrativa chilena escrita por sus -más o menos - coetáneos (Edwards, Lafourcade, el mismo Mauricio Wacquez, por citar tres nombres) y, luego, en el contexto póstumo de los novelistas que han emergido después: es decir, cómo influyó Donoso a narradores como Gonzalo Contreras, Jaime Collyer, Arturo Fontaine, Carlos Franz, Alberto Fuguet, si es que los influyó. ¿Qué significa exactamente "influir"? Y aun, si es que, a otros más jóvenes o más "recientes" como Pedro Lemebel, Rafael Gumucio, Roberto Brodsky, Pablo Simonetti. Hasta el propio Roberto Bolaño, que hablaba con sorna de los "donositos", creando así un gran malentendido entre humorístico y encarnizado. Pero no puedo hablar de todo eso, o no quiero. No todavía.

Si esto es un homenaje o, más bien, una evocación de José Donoso, y sobre todo de José Donoso “en España”, porque aquí vivió varios años y aquí fue publicado con cierta resonancia, tengo que empezar por el principio, que no puede sino ser "mi" principio. O sea, tengo que empezar por mi propia experiencia de José Donoso cara a cara. Esa experiencia comenzó en 1981, en Santiago de Chile, creo que en el otoño austral, cuando leí en un periódico que el escritor había regresado a Chile (dejaba España) y se proponía dirigir en la capital chilena un taller de cuentos al que uno podía postular enviando un par de relatos. Ese taller de cuentos, al que fui admitido, se transformaría más tarde en taller de 
novelas incipientes —algunas han sido publicadas años más tarde_- de donde me ha quedado el trauma de no poder terminar yo mismo ninguna novela todavía, y quién sabe si será mejor así, aunque nunca se sabe.

Donoso tenía entonces 57 años. Unos meses antes, durante una primera "incursión de retorno a Chile" del escritor, un amigo mío, Antonio de la Fuente, le había hecho una entrevista para la revista $L a$ Bicicleta, publicación en la que yo mismo iba a trabajar dos años después. Una noche, en una añosa habitación del mismo barrio donde vivió Pablo Neruda en su juventud, en la calle Maruri, escuchamos la grabación de esa entrevista en una cassette. Cuando a Donoso le preguntaban su opinión por la obra de Antonio Skármeta (autor de Ardiente paciencia, la novela que daría lugar a la película El cartero), respondió: "Lo que está escribiendo Skármeta no me interesa para nada. En cambio, me interesa mucho lo que hace Mauricio Wacquez". Evoco ese detalle ahora porque en alguna de las sesiones del taller, en 1981 o 1982, le recordé aquella opinión. Me miró con ojos un poco malignos, disimulados o engañosos detrás de las gafas: “¿Yo dije eso?”, preguntó: “Mira, lo que escribe Wacquez me parece una tontería y, en cambio, creo que Skármeta es muy interesante". Desconcertado, no dije nada. No tengo idea de qué diría Donoso hoy si estuviese aquí, ante la misma pregunta, pero lo curioso, y tal vez lo fascinante, y así resultó en ese momento para mí, era constatar cómo él se permitía cambiar de opinión de una semana a otra con total desparpajo. No eran, por supuesto, opiniones trascendentales, no se jugaba en ellas ningún principio moral de carne y hueso, sino que eran la mirada oblicua e irónica — provocadora en su volubilidad - que Donoso lanzaba a menudo sobre los textos de tal o cual autor. Creo que no sólo se permitía esa flexibilidad impredecible, sino que además se la proponía conscientemente, como un componente esencial de la sensibilidad ante la literatura. Fluctuaciones de ese tipo forman parte, por lo demás, de la experiencia de todos nosotros, pero el autor de Coronación y Este domingo hacía de ellas una ostentación casi orgullosa.

Esto es una hipótesis mía, nada más que eso, pero tal vez no sea arbitrario esbozarla: José Donoso vivía, como escritor, en el filo de una navaja, la navaja del fracaso, puesto que él buscaba el éxito. Y el éxito, más allá de la autonomía económica y el renombre mundano, por llamarlo así, consistía para Donoso en ser un buen novelista, en escribir novelas artísticamente válidas, y él, es lo que creo, nunca estaba 
del todo seguro de haberlo conseguido. A Donoso le gustaba hablar de la "fisura" que impulsa, compensatoriamente, a un escritor a inventar mundos de ficción con la palabra, y con ello se refería a una carencia, una herida en la propia existencia, algo que nos dice que somos o estamos incompletos, y que por lo tanto no merecemos ser amados "completamente". Donoso tenía fisuras, sin duda, y más de una vez nos habló de ellas. Y una de ellas era, para él, no estar seguro de ser un gran escritor, ni siquiera un buen escritor: José Donoso no estaba seguro. Si su opinión sobre sí mismo en ese sentido era variable, ¿qué esperar de sus opiniones sobre los demás escritores chilenos? Digo "chilenos", porque el medio literario chileno es, y lo era mucho más en esa época, hace 25 años y en plena dictadura, una minúscula olla de grillos, un infierno endogámico, una familia pequeña de hermanos celosos y recelosos. Se dice que en la personalidad básica de los chilenos existen actitudes y aficiones como el "pelambre" y el "chaqueteo", formas pueblerinas de la envidia. La envidia es un pecado capital que exige, para que opere la redención creativa, una conciencia desdoblada de sí mismo. No lo digo en un sentido religioso, sino psicológico. Todos sentimos envidia alguna vez y no está mal conocer esa envidia propia. Donoso conocía sus envidias, es decir, conocía - y de algún modo reverenciaba- su propia fisura, y eso lo impulsaba hacia adelante, como un Sísifo que más de una vez —aunque nunca estuviera seguro - logró arrojar la roca hacia el otro lado del monte. La arrojó, sí, porque, mal que le pese o no le pese a él mismo, Donoso "triunfó". Si no, no estaríamos aquí.

Cuando llegó de vuelta a Chile se acababa de publicar, si no me equivoco, su novela El jardín de al lado, un relato ambientado en esta misma ciudad, Madrid, en pleno verano, y donde el sol implacable cae sobre el pozo de envidia que atormenta al protagonista Julio Méndez, y pone a hervir sin piedad ese caldo amargo y desesperado. Es una novela sobre el fracaso, o sobre la tentación del fracaso, o sobre la vocación del fracaso, y siempre sobre el pavor al fracaso. Es, además, una novela sobre la duplicidad, algo que - entre otros signos - se hará evidente en el desdoblamiento del narrador al final del libro. Julio envidia hasta la médula al deslumbrante novelista ecuatoriano Marcelo Chiriboga, a la vez que se siente manipulado por las garras de la agente literaria Núria Monclús. Esta Núria es una metempsícosis, como todos saben, de Carmen Balcells, y a Chiriboga me lo imagino yo como un engendro que reúne lo mejor (literariamente hablando) de García Márquez, 
Vargas Llosa, Carlos Fuentes, Julio Cortázar. Piensen en esos autores a mediados de los años 70: eran como dioses que estaban en plena forma, casi jóvenes aún, y Donoso quería ser un dios de ese Olimpo (y tal vez lo fue), pero temía ser tan sólo un titán, un Prometeo, un genio intermedio que se acercaba a nosotros para intentar enseñarnos en su taller el uso del fuego. $\mathrm{Y}$ ese fuego era, como sabemos, un delicado juego de engaños voluntarios que escondían una sustancia veraz pero, a la vez, intangible.

Un juego de máscaras, evidentemente. En su taller, Donoso enseñaba no un modo de escribir, no un estilo semejante al suyo, sino, tal vez sin proponérselo, una actitud frente a la literatura como actividad. ¿Por qué me maravillaba oírlo hablar, aunque no estuviera de acuerdo con sus juicios? Porque veía algo que en el Chile de hace 25 o 30 años no existía: un escritor "profesional". "Profesional" es, en este caso, una palabra peligrosa, de doble filo. Permítanme recordar un momento de aquellas veladas en la buhardilla donde el taller funcionaba. Una de las primeras tareas que Donoso nos encomendó fue leer Los papeles de Aspern, de Henry James, novela breve ambientada en Venecia a fines del siglo XIX, y cuyo protagonista es un verdadero fetichista, capaz de todo con tal de obtener las cartas de amor de un célebre poeta muerto hace varias décadas (y cuyo referente histórico serían, tal vez, los poetas ingleses Byron y Shelley). Donoso, una noche, nos hizo leer por turnos el texto en voz alta. En el momento en que la góndola del protagonista se detiene frente al palazzo de las señoritas Bordereau, James corta de golpe una larga reflexión del narrador para poner, bruscamente, el objeto del deseo (el palazzo y lo que allí dentro se guarda) frente a nuestras narices. Ese cambio de ritmo le parecía a Donoso magistral. Detuvo la lectura con un gesto y dijo: "En este cambio de párrafo me encuentro con un profesional". El profesional era Henry James, y lo era por su manejo de la narración, al menos en opinión de Donoso. Un profesional es, entonces, alguien que domina su oficio a un nivel de excelencia, como dicen ahora los resabidos. Pero también, en otra acepción, puede ser alguien que vive formalmente de su oficio. Donoso aspiraba a lograr ambas cosas. Quería ser un escritor hasta el último pelo de la barba, y, nos gusten mucho o poco sus libros, lo era inevitablemente. Sólo vivía para ser escritor, y se notaba. Eso, en el Chile de esos años que ya nos parecen inimaginables en su sordidez intelectual, o en su aislado provincianismo, era algo muy raro, y por lo tanto nos maravillaba. $\mathrm{O}$ 
al menos a mí. Me conmovía, incluso, y es que José Donoso parecía estar construyendo cada día, molécula a molécula, un ser humano -él mismo- que se constituía a partir del ejercicio de la ficción literaria. Y qué es la ficción escrita sino un juego de palabras leído como si fuese el recuerdo de lo real. Era como si el artificio, llevado a su límite existencial, constituyera una esencia. Una máscara esencial, si cabe la expresión.

Bueno, es así como yo lo veía, en aquel primer ciclo de su taller (de 1981 a 1983), y es como lo vi doce años más tarde, cuando, trabajando como editor en Alfaguara Chile, debí revisar con Donoso el manuscrito de la novela que él acababa de terminar, Donde van a morir los elefantes, primero (y era su primer libro publicado en ese sello), y un año más tarde los relatos de Conjeturas sobre la memoria de mi tribu. No eran, ya, sus mejores libros, pero en ambos, o mejor dicho en el trabajo de revisar y corregir junto al autor los manuscritos de esos dos libros, sentí que estaba tratando con alguien empeñado en ser un escritor a tiempo completo, un escritor hasta el fin que asomaba ya en los meses venideros. En efecto, ese fin no estaba tan lejos, y llegaría en diciembre de 1996.

Pero antes hubo un gesto final, y su contradicción ambivalente. Donoso buscaba tan obsesivamente mezclar o fundir o relacionar la vida a secas con la ficción, que en Conjeturas sobre la memoria de mi tribu — su último libro- tomó ciertas historias familiares, sucesos que se habían ido moldeando de una generación a otra mediante la repetición, pero también mediante la habladuría y la reinvención, y quiso dar, en el mismo libro, distintas versiones posibles de por qué, por ejemplo, una tía suya había sido recluida muy joven en un convento de monjas de clausura. ¿Era a causa de un embarazo, de un adulterio, de una conveniencia social de otra índole? ¿Era un castigo caprichoso a la simple desobediencia? ¿Era una pura opción de aquella muchacha que iba a envejecer sin ser nunca más vista por ojos humanos? Donoso iba extremando su concepción de la ficción como algo que el narrador puede componer y descomponer de manera consciente y retrospectiva. Mientras revisábamos el manuscrito, yo intuía que este relato sobre la tía monja y secreta (y es sólo uno de los relatos, porque había otros que Donoso debió o escogió autocensurar, ya hablaremos de ello) no era simplemente contar la "misma historia" desde el punto de vista de distintos personajes o narradores, sino algo más, algo difícil quizás de pre- 
cisar, o de distinguir conceptualmente de maniobras narrativas que hayan hecho antes otros escritores, pero que en esos momentos me parecía furiosamente donosiano. Era como introducirse la voz narradora en la historia contada, opinando, sí, pero además vacilando, "conjeturando" (como señala el título del libro), y conjeturando sobre la conjetura. ¿Cómo ponerle punto final a un libro así? Los plazos de la editorial urgían cuando, de pronto, surgió un problema adicional.

Una tarde calurosa de enero, creo, de 1996, estábamos en su estudio - Donoso ataviado con una chilaba blanca - cuando anuncian que el cartero trae un paquete. Existían todavía los carteros en el imaginario consciente. El paquete eran libros del propio José Donoso, libros que él había enviado de regalo a unos parientes y que ahora éstos le devolvían en un arrebato de indignación. Abrió la carta adjunta, la leyó y con cara de fantasma me la pasó. "Lee esto", me dijo: "Se jodió la novela". Yo no entendía nada. ¿Qué sucedía? Pues, que como este libro en progreso consistía en conjeturas sobre la memoria de su tribu, o sea, de su familia extendida hacia atrás en tres generaciones, Donoso había enviado manuscritos parciales a sus parientes vivos para saber qué opinaban. Y uno de ellos opinó muy mal. Opinó pésimo. Era un abogado muy emplumado y circunspecto, según me han dicho, primo del escritor, y estaba furioso hasta la legalidad por el retrato de un tío abuelo común, un político chileno de los años 20 o 30, fundador del diario La Nación y cuyo nombre era, justamente, el de la avenida en cuya esquina se ubicaba en aquel tiempo la casa de Alfaguara en Santiago, donde yo trabajaba. Furioso hasta la legalidad, porque amenazaba a Donoso con querellarse o demandarlo por injurias post mortem o algo así, por asesinar la imagen, tal vez, del célebre Eliodoro Yáñez. ¿Cuál era la injuria? Entre otras cosas, insinuar la posibilidad de que la abuela de ese político muerto hacía muchos años había sido, quién sabe si en el siglo XIX, una suerte de "cabrona", la regenta de un prostíbulo, una mujer que viajaba a las zonas rurales aledañas a Santiago para reclutar, con falsas promesas, a muchachas campesinas a las que convertía más tarde en prostitutas. ¿Era eso? ¿O era que la antepasada, bisabuela o tatarabuela del primo abogado y del escritor, había sido ella misma una de esas muchachas, ya que no la regenta (llamada, si no me equivoco, Peta Ponce)? ¿Y era ella la madre de don Eliodoro Yáñez, de quien sus adversarios políticos, conservadores y aristócratas (ipero ya muertos y 
remuertos todos!) podrían decir ahora, con conjeturada propiedad, que era un hijo de la gran puta?

José Donoso, demudado, pálido, abatido, había perdido el habla. Yo le decía, por supuesto, "dale no más con todo, que se querellen, así el libro se va a vender mucho más". Pero fue inútil. Hubo que parar las máquinas de la revisión, Donoso se puso a reescribir capítulos, y debí ayudarlo a "coser" párrafos que antes estaban separados, sugerir elipses, en fin, desconjeturar las conjeturas de aquella historia de monjas y prostitutas emparentadas por la pluma que ahora temblaba sin razón. Intentaba, en las pausas, convencerlo de que endureciera tripas y publicara el libro tal cual, pero él no quería o no se atrevía. Hubo muchos conciliábulos con otros primos, creo que con un nieto de Eliodoro Yáñez (es decir, con un hijo del escritor Juan Emar), asambleas que yo, un intruso circunstancial, sólo oía desde el otro lado de los ventanales. Y, finalmente, José Donoso cedió, autocensurando vastos párrafos — que todavía conservo bajo el polvo- de sus Conjeturas sobre la memoria de mi tribu. ¿Lo había tocado el rayo de una súbita delicadeza familiar? Tengo mis propias conjeturas: ya debilitado por la enfermedad que lo llevaría a la muerte unos meses más tarde, el novelista que jugaba con las máscaras de sus personajes para imaginar la suya propia, en el filo de la navaja no sólo del éxito o el fracaso artísticos (en su propia percepción), sino también en el filo de la navaja de la trasgresión social, léase sexual (y basta leer El lugar sin límites o, más metafóricamente, El obsceno pájaro de la noche), en una época que no era todavía lo que es hoy el mundo, bueno, tal vez - es una hipótesis o una conjetura, sólo eso- Donoso tuvo miedo de que, involucrado en un escándalo con energúmenos legalistas, afloraran públicamente esos aspectos de su sexualidad de los que siempre, desde que yo tengo memoria editorial o literaria, se habló en Chile. ¿Era José Donoso heterosexual, homosexual, bisexual o asexual, experiencialmente hablando? Creo que ni lo primero ni lo último. Tuvo miedo, y entonces recordé que en una sesión del taller él había hecho una especie de elogio de la cobardía como mecanismo adaptativo, algo que aquella vez no entendí del todo. Tuvo miedo $y$, sin embargo, era muy valiente. Censuró su propio libro, pero enfrentaba su destino allí, entre las cuatro paredes de la literatura, con valor. Se dice que valiente no es el que no siente miedo, sino él que sabe que lo siente y, sobreponiéndose a él, actúa de todos modos. Bueno, en 1996 —el último año de su vida—, amenazado por la enfermedad, 
reflexionando después de quién sabe qué argumentaciones de primos, tíos y amigos, Donoso tuvo miedo y cedió. U optó. Pero en un sentido más general tenía otros miedos ante los que no se arredró: aquel miedo, sobre todo, de no ser un gran escritor, queriendo serlo con toda el alma. Para muchos lectores lo es, para muchos otros no. Eso aquí no importa demasiado. Temía no ser un buen novelista y, aun así, se empeñaba en escribir cuando las fuerzas lo abandonaban. Lo recuerdo trepando por la escalera que llevaba a su estudio en el ático, empeñado en redactar todavía una frase más, aunque luego decidiera borrarla por ética o por estética. Censuró su último libro publicado en vida, y censuró parte de sí mismo a los ojos de los demás. Temía que tras las máscaras no hubiese nada, pero a la vez sabía, como en una paráfrasis del poema "Ítaca" de Kavafis, que lo medular no era tal vez encontrar un rostro detrás de la máscara, sino el proceso de crear máscaras y, luego, de apartarlas para ver si había o no un rostro siempre elusivo bajo ellas. ¿Era ésa su esencia? Temía, también, a su presunta (digamos) homosexualidad, aunque tal vez no como experiencia personal, sino como cualidad definitoria del personaje de sí mismo —el escritor — que él había construido, y no sin mérito. Temía "ser leído como un autor homosexual", aunque ese temor al reduccionismo era o es infundado: José Donoso es un novelista ni hetero-ni homosexual, si es que caben semejantes calificativos, sino un novelista agudamente consciente de que, con sexo de por medio o sin él, los seres humanos se debaten en identidades lábiles, movedizas, ambivalentes, acomodaticias, insuficientes, algo que él describió en sus narraciones con muy diversas formas de trasvasije de géneros, de clases, de destinos felices e infelices: ahí está la travestida Manuela de $E l$ lugar sin límites — que es mujer y es padre, como en la prefiguración de algún personaje de Almodóvar-, ahí está la secreta voz conyugal que juega a ser Julio Méndez en El jardín de al lado, ahí está el narrador exasperado, lleno de dudas, cobarde y valiente, profesional en el mejor sentido, de Conjeturas sobre la memoria de mi tribu.

Madrid, octubre de 2007. 